\title{
Open
}

Review

\section{Hydrogen sulfide and translational medicine}

\author{
Wei GUO ${ }^{1}$, Ze-yu CHENG ${ }^{1}$, Yi-zhun ZHU ${ }^{1,2,3, *}$ \\ ${ }^{1}$ Department of Pharmacology, School of Pharmacy and ${ }^{2}$ Institute of Biomedical Sciences, Fudan University, Shanghai 201203, China; \\ ${ }^{3}$ Department of Pharmacology, National University of Singapore, Singapore
}

Hydrogen sulfide $\left(\mathrm{H}_{2} \mathrm{~S}\right)$ along with carbon monoxide and nitric oxide is an important signaling molecule that has undergone large numbers of fundamental investigations. $\mathrm{H}_{2} \mathrm{~S}$ is involved in various physiological activities associated with the regulation of homeostasis, vascular contractility, pro- and anti-inflammatory activities, as well as pro- and anti-apoptotic activities etc. However, the actions of $\mathrm{H}_{2} \mathrm{~S}$ are influenced by its concentration, reaction time, and cell/disease types. Therefore, $\mathrm{H}_{2} \mathrm{~S}$ is a signaling molecule without definite effect. The use of existing $\mathrm{H}_{2} \mathrm{~S}$ donors is limited because of the instant release and short lifetime of $\mathrm{H}_{2} \mathrm{~S}$. Thus, translational medicine involving the sustained and controlled release of $\mathrm{H}_{2} \mathrm{~S}$ is of great value for both scientific and clinical uses. $\mathrm{H}_{2} \mathrm{~S}$ donation can be manipulated by different ways, including where $\mathrm{H}_{2} \mathrm{~S}$ is given, how $\mathrm{H}_{2} \mathrm{~S}$ is donated, or the specific structures of $\mathrm{H}_{2} \mathrm{~S}$-releasing drugs and $\mathrm{H}_{2} \mathrm{~S}$ donor molecules. This review briefly summarizes recent progress in research on the physiological and pathological functions of $\mathrm{H}_{2} \mathrm{~S}$ and $\mathrm{H}_{2} \mathrm{~S}$ releasing drugs, and suggests hope for future investigations.

Keywords: hydrogen sulfide; $\mathrm{K}_{\text {ATP }}$ channel; calcium channel; TRPA1; NF-KB; cytochrome oxidase; antioxidant; $\mathrm{H}_{2} \mathrm{~S}$ donor; $\mathrm{H}_{2} \mathrm{~S}-\mathrm{releasing}$ drug; translational medicine

Acta Pharmacologica Sinica (2013) 34: 1284-1291; doi: 10.1038/aps.2013.127

\section{Introduction}

Hydrogen sulfide $\left(\mathrm{H}_{2} \mathrm{~S}\right)$ is a colorless, gaseous molecule at room temperature. It is widely known and disliked for its pungent, rotten egg-like smell. $\mathrm{H}_{2} \mathrm{~S}$ is very water-soluble and lipophilic, resulting in quick and convenient transport between cells and tissues ${ }^{[1]}$. It is also strongly toxic, especially to the central nervous system. In fact, $\mathrm{H}_{2} \mathrm{~S}$ acts as a more potent inhibitor of mitochondrial respiration than cyanide ${ }^{[2]}$. The maximum concentration in the air is approximately 10 $\mathrm{mg} / \mathrm{m}^{3}$, and high concentrations of $\mathrm{H}_{2} \mathrm{~S}$ may cause an instant loss of olfactory sensation or fainting. However, $\mathrm{H}_{2} \mathrm{~S}$, resembling $\mathrm{CO}$ and $\mathrm{NO}$, is converted from a noxious molecule to a signaling molecule that may have promise in the medical and pharmaceutical fields.

Endogenous $\mathrm{H}_{2} \mathrm{~S}$ is produced from $L$-cysteine by both CSE and CBS, with the cofactor cysteine amino transferase, through a so-called "trans-sulfuration pathway" ${ }^{[3-5]}$. Both CSE and CBS enzymes are pyridoxal-5'-phosphate-dependent with different concentrations in various tissues. It was previously reported that CBS is predominantly located in the central nervous system (hippocampus, cerebellum, cerebral cortex, and brain stem ${ }^{[6]}$, while CSE emerges more in the car-

\footnotetext{
* To whom correspondence should be addressed.

E-mail zhuyz@fudan.edu.cn

Received 2013-06-09 Accepted 2013-08-12
}

diovascular system (aorta, mesenteric artery, portal vein, and other vascular tissue $)^{[7,8]}$. An amount of CBS or CSE is tissuespecific, and coincidence and sole incidence are both allowed. A recent investigation also suggests the presence of another enzyme besides CBS and CSE that can generate endogenous $\mathrm{H}_{2} \mathrm{~S}$ : 3-MST, which generates $\mathrm{H}_{2} \mathrm{~S}$ from cysteine with the help of a-ketoglutarate in the brain ${ }^{[9]}$. 3-MST is located in the liver, kidney, heart, lung, thymus, testis, thoracic aorta, and brain. Three pathways of $\mathrm{H}_{2} \mathrm{~S}$ degradation exist: (1) desulfurization to thiosulfate by mitochondrial oxidation, then to sulfite or sulfate; (2) cytosolic methylation to dimethylsulfide; and (3) sulfhemoglobin formation by the binding to hemoglobin ${ }^{[9,10]}$. A previous investigation shows that after $\mathrm{H}_{2} \mathrm{~S}$ is synthesized, it is quickly absorbed or stored as a form of bound or acid-labile sulfur, while free $\mathrm{H}_{2} \mathrm{~S}$ is maintained at a baseline level ${ }^{[11]}$. Bound sulfur is stored intracellularly in neurons and astrocytes of rats and releases $\mathrm{H}_{2} \mathrm{~S}$ in the presence of physiologic concentrations of the endogenous reducing substances glutathione and cysteine. Acid-labile sulfur is another form of stored $\mathrm{H}_{2} \mathrm{~S}$. It localizes in the mitochondria and the release of $\mathrm{H}_{2} \mathrm{~S}$ occurs at a $\mathrm{pH}$ below 5.4 .

Methods to study $\mathrm{H}_{2} \mathrm{~S}$ conventionally included three aspects. First, changes in substances involved in the down-regulation of the $\mathrm{H}_{2} \mathrm{~S}$ concentration, such as CBS and CSE antagonists and inhibitors of potent targets are observed. Second, symptoms are compared between a range of $\mathrm{H}_{2} \mathrm{~S}$ concentrations 
by enhancing the dosage of $\mathrm{H}_{2} \mathrm{~S}$, mainly through exogenous $\mathrm{H}_{2} \mathrm{~S}$ donors, such as NaHS or other $\mathrm{H}_{2} \mathrm{~S}$-releasing compounds. Third, the variance in $\mathrm{H}_{2} \mathrm{~S}$ concentration in certain diseases is measured, and the function of this variability is determined. The effort put into studying the pathological and physiological functions of $\mathrm{H}_{2} \mathrm{~S}$ has allowed for a general understanding of its behavior in the body, including its synthesis, metabolism, potent targets, and effects. The large amount of evidence gathered through various experiments and observations has shown that the role of $\mathrm{H}_{2} \mathrm{~S}$ as a vital endogenous gasotransmitter is ubiquitous throughout the human body. The use of $\mathrm{H}_{2} \mathrm{~S}$ in the central nervous system, cardiovascular system, and gastrointestinal system is promising, and the investigation of its role is important because cardiovascular and cerebrovascular diseases as well as gastrointestinal cancers are among the top causes of human mortality. Hence, a breakthrough in dealing with diseases that severely affect our health in hope of longevity to occur is necessary. Furthermore, $\mathrm{H}_{2} \mathrm{~S}$-associated drugs with effectiveness similar to that of nitroglycerin in cases of angina pectoris may be developed in the future.

\section{Recent evidence for the therapeutic application of $\mathbf{H}_{2} \mathbf{S}$}

Since 1996, when Ade and Kimura began their investigation of $\mathrm{H}_{2} \mathrm{~S}$, the role of $\mathrm{H}_{2} \mathrm{~S}$ has been gradually revealed by various contributions from scientists worldwide ${ }^{[3]}$. Recent discoveries regarding $\mathrm{H}_{2} \mathrm{~S}$ demonstrate its critical importance, much like $\mathrm{NO}$ and $\mathrm{CO}$, to the medical field. This small, gaseous molecule appears to be both powerful and ubiquitous.

In the central nervous system, $\mathrm{H}_{2} \mathrm{~S}$ ameliorates ischemic injuries but leads to the aggravation of stroke. Enhancement of the $\mathrm{H}_{2} \mathrm{~S}$ concentration in the brain induces brain infarct, while CBS or CSE inhibitors can reverse this effect. The role of $\mathrm{H}_{2} \mathrm{~S}$ in neuron protection has been shown in glutamateinduced death with increasing concentrations of cysteine and Y-glutamylcysteine, which causes enhanced GSH concentrations ${ }^{[11-14]}$. In patients with $\mathrm{AD}$, localized increases in $\mathrm{H}_{2} \mathrm{~S}$ resulted in a delay of aggravation and exacerbation of symptoms ${ }^{[13,15,16]}$. In addition, patients with Down syndrome overproduce $\mathrm{H}_{2} \mathrm{~S}$ because their urinary excretion of thiosulfate, a specific $\mathrm{H}_{2} \mathrm{~S}$ end product, was increased, suggesting a positive relationship between $\mathrm{H}_{2} \mathrm{~S}$ concentration and the aggravation of Down syndrome ${ }^{[16-18]}$.

In the cardiovascular system, $\mathrm{H}_{2} \mathrm{~S}$ is related to hypertension, atherosclerosis, and myocardial injury. Its utility for treating hypertension may correspond to its vasodilatory effect. $\mathrm{H}_{2} \mathrm{~S}$ has the ability to relax the rat thoracic aorta, portal vein, and mesenteric artery, which suggests a more fundamental role in the regulation of contractility and blood pressure ${ }^{[19-23]}$. Conversely, further study has suggested that $\mathrm{H}_{2} \mathrm{~S}$ is a vasoconstrictor at low concentrations with a possible mechanism for suppressing NO, which is also involved in contractility. As plaque is destabilized and aortic smooth muscle cell proliferation is possibly reduced by $\mathrm{H}_{2} \mathrm{~S}$, atherosclerosis is also palliated owing to an enhanced $\mathrm{H}_{2} \mathrm{~S}$ concentration ${ }^{[24,25]}$. Similarly, $\mathrm{H}_{2} \mathrm{~S}$ is able to help patients recover from myocardial injury, particularly ischemia-reperfusion injury ${ }^{[26-31]}$. In summary, many cardiovascular diseases demonstrated a relationship with $\mathrm{H}_{2} \mathrm{~S}$ modulation, prognosticating a comprehensive utility of $\mathrm{H}_{2} \mathrm{~S}$ in heart diseases.

In the respiratory system, investigation into the link between $\mathrm{H}_{2} \mathrm{~S}$ and pulmonary hypertension was the first research in the field of pathophysiology and $\mathrm{H}_{2} \mathrm{~S}$ in the world ${ }^{[32]}$. In recent years, many investigations examining the role of $\mathrm{H}_{2} \mathrm{~S}$ in pulmonary hypertension, in which $\mathrm{H}_{2} \mathrm{~S}$ was administered to models of chronic hypoxia, have been conducted ${ }^{[3,34]}$.

In the gastrointestinal system, $\mathrm{H}_{2} \mathrm{~S}$ remains important in the regulation of local homeostasis. $\mathrm{H}_{2} \mathrm{~S}$-releasing bacteria in the intestine are a major source of endogenous $\mathrm{H}_{2} \mathrm{~S}$. Donation of $\mathrm{H}_{2} \mathrm{~S}$ contributes to chloride secretion, which aggravates certain types of gastritis ${ }^{[35]}$. Gastrointestinal contractility shows sensitivity to $\mathrm{H}_{2} \mathrm{~S}$, which affects the gastrointestinal smooth muscle cells as well as the neurons in the enteric nervous system $^{[15,35,36]}$. The concentration of $\mathrm{H}_{2} \mathrm{~S}$ is enhanced when abdominal sepsis or endotoxemia occurs, and administration of $\mathrm{H}_{2} \mathrm{~S}$ leads to exacerbation of these conditions, mainly because of its pro-inflammatory effect ${ }^{[36,37]}$. Apart from these negative effects, $\mathrm{H}_{2} \mathrm{~S}$ has been shown to have a protective antiinflammatory effect on the gastrointestinal system in some types of gastritis and colitis ${ }^{[38-40]}$. An obvious contradiction, thus, emerges, leading to puzzling study results in terms of the actual pro- or anti-inflammatory effects of $\mathrm{H}_{2} \mathrm{~S}$. This conflict implies the presence of fundamental unknown mechanisms in addition to those that have been observed. The observed results may be derived from a balance of multiple mechanisms because a balanced result always changes with circumstances.

Furthermore, insulin secretion and diabetes mellitus can be affected by local $\mathrm{H}_{2} \mathrm{~S}$ concentrations because the pancreas is among the targets of $\mathrm{H}_{2} \mathrm{~S}^{[41-44]}$. In the pancreas, CSE is the main enzyme converting cysteine to $\mathrm{H}_{2} \mathrm{~S}$. It has also been reported that the concentration of $\mathrm{H}_{2} \mathrm{~S}$ rose in response to the presence of pancreatitis, which is ascribed to its pro-inflammatory effect. Therefore, it is clear that $\mathrm{H}_{2} \mathrm{~S}$-releasing drugs may make a difference in pancreatitis or diabetes. However, the functions of $\mathrm{H}_{2} \mathrm{~S}$ remain ambiguous and demand further investigation to elucidate its anfractuous signaling network. Current studies suggest that the effects of $\mathrm{H}_{2} \mathrm{~S}$ are often influenced by its concentration and reaction time as well as the cell and disease type it is acting upon. Hence, the application of $\mathrm{H}_{2} \mathrm{~S}$ in certain dysfunctions is bound to be difficult considering its potentially low specificity for certain organs and tissues (see Figure 1). On the other hand, various uses of $\mathrm{H}_{2} \mathrm{~S}$ may be possible because of its power.

\section{New therapeutic targets associated with $\mathrm{H}_{2} \mathrm{~S}$}

The mechanisms and pathways of $\mathrm{H}_{2} \mathrm{~S}$ signaling are not yet completely understood. The regulation of $\mathrm{H}_{2} \mathrm{~S}$ is so complicated that new mechanisms are continuously discovered before the former mechanisms are fully understood. Fortunately, several fundamental mechanisms have been determined and have drawn much attention, and we have gradually begun to fully understand them (shown in Figure 2). 


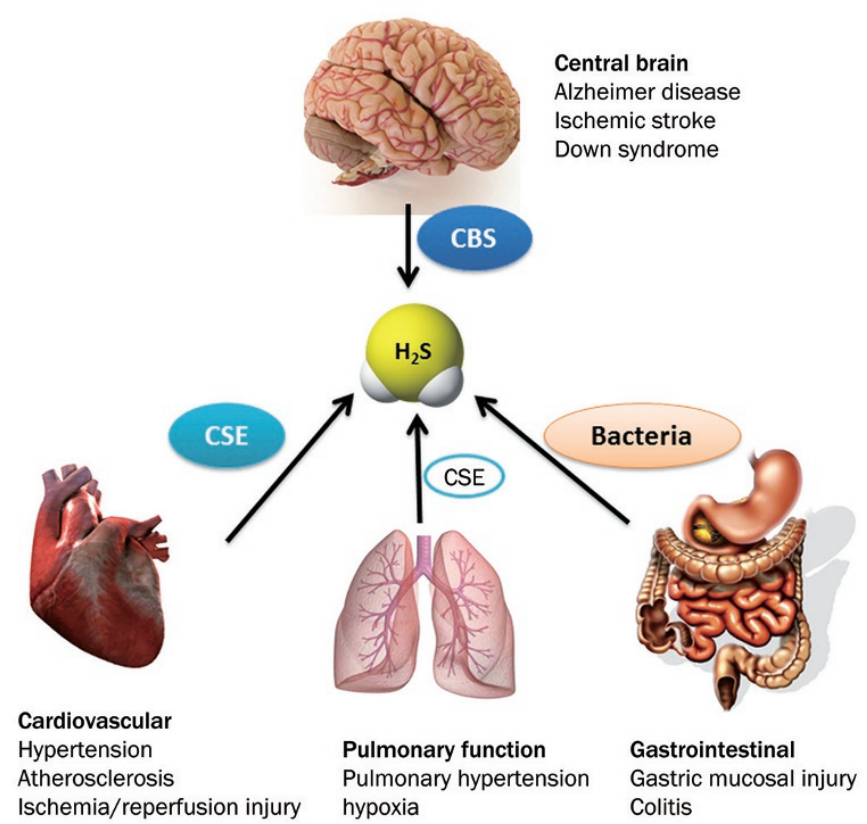

Figure 1. Schematic of the involvement of $\mathrm{H}_{2} \mathrm{~S}$ in various physiological and pathological functions.

\section{Activation of $\mathrm{K}_{\text {ATP }}$ channels}

A hallmark role of $\mathrm{H}_{2} \mathrm{~S}$ is the regulation of contractility, which is the most fundamental and valuable use of $\mathrm{H}_{2} \mathrm{~S}$. The mechanism directing this effect is a major research topic. Vasodilation has been shown to be caused by the activation of the $\mathrm{K}_{\mathrm{ATP}}$ channel $^{[8,26,45]}$. Evidence for this hypothesis comes from the observation that the vasodilatory effect of $\mathrm{H}_{2} \mathrm{~S}$ is attenuated by $\mathrm{K}_{\mathrm{ATP}}$ channel antagonists, such as glibenclamide, while the $\mathrm{K}_{\mathrm{ATP}}$-dependent current is increased by $\mathrm{H}_{2} \mathrm{~S}$, as shown by patch-clamp technology. In another study, the non-selective $\mathrm{K}_{\text {ATP }}$ channel antagonist glibenclamide, the selective $\mathrm{K}_{\mathrm{ATP}}$ channel antagonist HMR-1098, and the selective mitochondrial $\mathrm{K}_{\mathrm{ATP}}$ channel antagonist 5-HD were compared to show the effect of $\mathrm{H}_{2} \mathrm{~S}$ on the $\mathrm{K}_{\text {ATP }}$ channel ${ }^{[46-48]}$. The results of this study suggest that $\mathrm{H}_{2} \mathrm{~S}$ selectively activates the plasma-membrane $\mathrm{K}_{\text {ATP }}$ channel (only 5-HD treatment lacked mediation of neuroprotection during hypoxia). In addition to having a vasodilatory effect, the activation of the $\mathrm{K}_{\mathrm{ATP}}$ channel preconditions the body against ischemia-reperfusion injury and promotes myocardial protection, which together provide a theoretical and experimental basis for the application of $\mathrm{H}_{2} \mathrm{~S}$ in heart disease ${ }^{[26,27,45]}$.

\section{Activation of T-type calcium channels}

Research has revealed that $\mathrm{H}_{2} \mathrm{~S}$ is involved in visceral painlike nociception and somatic hyperalgesia in mice. This observation led to further investigation of the role of indirect activation of T-type calcium channels in facilitation of visceral nociception ${ }^{[49-52]}$. Because $\mathrm{Zn}^{2+}$ acts as an inhibitor of T-type calcium channels, especially the $\operatorname{Cav}_{3.2}$ isoform, $\mathrm{H}_{2} \mathrm{~S}$, which chelates $\mathrm{Zn}^{2+}$, is reasonably regarded to indirectly activate $\mathrm{T}$-type calcium channels by inhibiting $\mathrm{Zn}^{2+[53]}$. This hypothesis is further proven by the observation that $\mathrm{Zn}^{2+}$ chelates similarly to dipicolinic acid, showing the aggravation of colonic pain as well as hyperalgesia.

\section{Activation of TRPA1}

The TRP superfamily is comprised of nonselective cation channels that are divided into six main subfamilies: TRPC, TRPV, TRPM, TRPP, TRPML, and TRPA ${ }^{[54]}$. Among them, both TRPV and TRPA are important targets of pathological research. It is

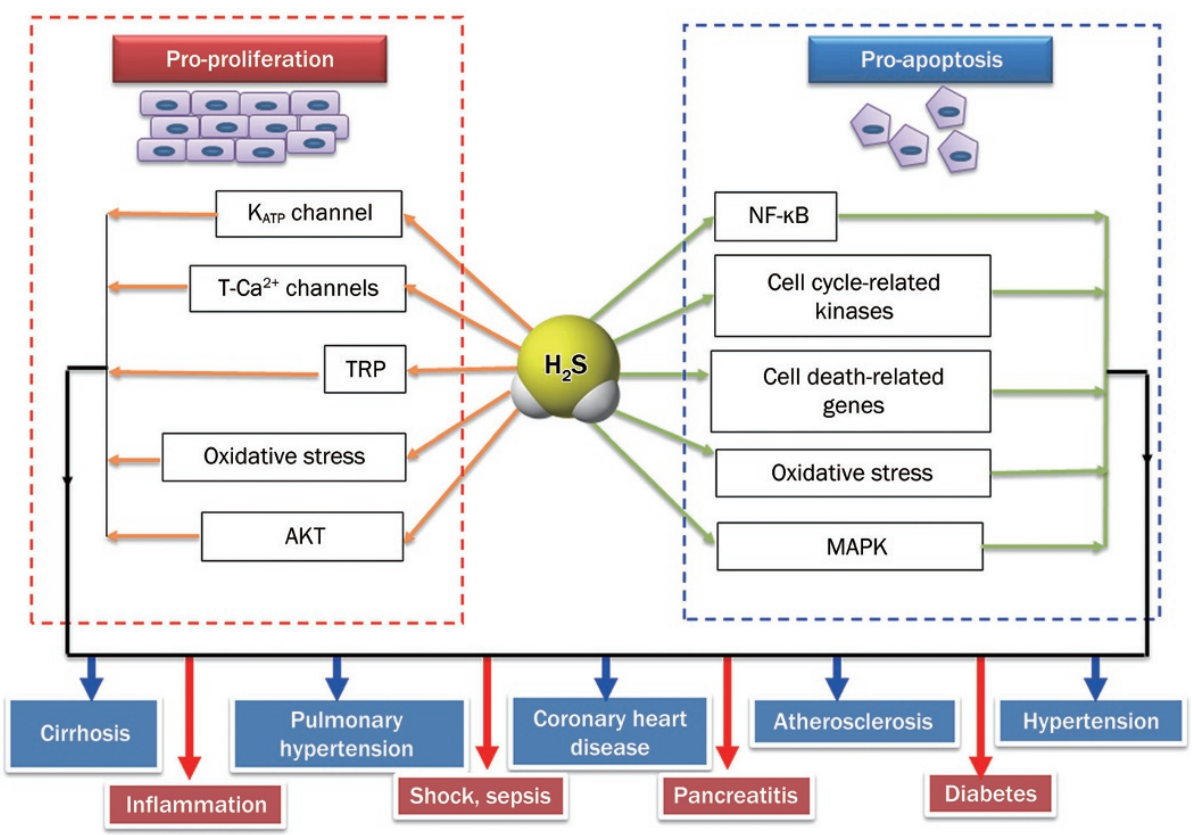

Figure 2. Potential involvement and application of the targets of $\mathrm{H}_{2} \mathrm{~S}$, including observed dual effects. 
well known that TRPV1 in the bladder wall produces detrusor overactivity. TRPA1 is present on unmyelinated sensory nerve fibers within the urothelium, suburothelial space, and muscle layer as well as around blood vessels throughout the bladder. Because TRPA1 coexists with TRPV1 in major loci, such as sensory neurons in rodent dorsal root and trigeminal ganglia, and because intracellular TRPA1 activators including allyl isothiocyanate and cinnamaldehyde also initiate detrusor overactivity resembling that caused by TRPV1, it is believed that TRPA1 is involved in sensory transduction ${ }^{[5]}$. A recent investigation demonstrated that $\mathrm{H}_{2} \mathrm{~S}$ activated TRPA1 in the presence of inflammation by the induction of calcium responses in TRPA1-expressing $\mathrm{CHO}$ cells. Moreover, this result is suppressed by ruthenium red, which is a nonselective TRP antagonist, and HC-030031, which is a selective TRPA1 antagonist. This reaction is not observed with the selective TRPV1 antagonist iodoresiniferatoxin. These findings reveal the presence of $\mathrm{H}_{2} \mathrm{~S}$-specific activation of TRPA1 channels ${ }^{[56]}$. Further investigation of $\mathrm{H}_{2} \mathrm{~S}$-specific TRPA1 channel activation may provide new solutions to various bladder disorders caused by hyperreflexia, and $\mathrm{H}_{2} \mathrm{~S}$ may affect nociception, which results from complicated functions of TRPA1, upon activation via the elicitation of pain, protective reflexes, and local release of neurotransmitters in the periphery.

\section{The NF-KB signaling pathway}

$\mathrm{H}_{2} \mathrm{~S}$-induced inflammation has a relationship with the NF- $\mathrm{KB}$ signaling pathway. This pathway is involved in cecal ligation and puncture-induced sepsis, in which $\mathrm{H}_{2} \mathrm{~S}$ regulates the expression of cytokines, chemokines, and adhesion molecules ${ }^{[57]}$. There are data indicating that the inhibition of SFKs causes the down-regulation of $\mathrm{H}_{2} \mathrm{~S}$-induced NF-KB activity and ICAM-1 expression, suggesting that $\mathrm{H}_{2} \mathrm{~S}$ is involved in regulating the activity of NF-KB by activating the phosphorylation of SFKs, eventually resulting in mediation of ICAM-1 expression ${ }^{[58]}$. This pathway may also be an answer to $\mathrm{H}_{2} \mathrm{~S}-$ induced anti-apoptosis. Mouse embryonic fibroblasts lacking p65, which is a subunit of NF- $\mathrm{kB}$, are sensitive to TNFa-induced cell apoptosis, indicating that NF-KB is a target molecule involved in apoptosis. Further research has elucidated a possible mechanism of enhanced transcription of CSE, which generates $\mathrm{H}_{2} \mathrm{~S}$, during TNF- $a$-induced apoptosis ${ }^{[6]} . \mathrm{H}_{2} \mathrm{~S}$ or sulfhydrates then generates the p65 subunit of NF-kB at cysteine-38 and binds to the coactivator ribosomal protein, S3. Finally, the promotion of anti-apoptotic genes occurs, including the cellular inhibitors of apoptosis, caspase-8-c-FLIP, A1, TRAF1, and TRAF2 ${ }^{[59]}$.

\section{Cytochrome oxidase}

$\mathrm{H}_{2} \mathrm{~S}$ has long been regarded as a strong toxin that inhibits mitochondrial respiration by combining the cytochrome $c$ oxidase copper and/or heme iron site, resembling hydrogen cyanide, a well-known lethal toxin ${ }^{[2]}$. Studies suggest that $\mathrm{H}_{2} \mathrm{~S}$ also binds and reduces ferric heme in microsomal cytochrome P450, generating a state of oxidative stress ${ }^{[60]}$. On the other hand, an interesting phenomenon called "suspended animation," a form of hypometabolism, results from the above mechanism. This phenomenon was first found in rodents that inhaled $\mathrm{H}_{2} \mathrm{~S}$ gas, and subsequent findings suggest that it is size-dependent or species-related ${ }^{[61-63]}$. Animals in suspended animation resembled those in hibernation, with reductions in cardiac output, ventilation frequency, and core temperature, finally leading to a decreased demand for energy. Hypometabolism can make great difference, if occurring in the human body, as an emergent protection against ischemia-associated tissue damage and infarction or providing a time delay in patients with stroke.

\section{A scavenger of reactive oxygen and nitrogen species}

$\mathrm{H}_{2} \mathrm{~S}$ is highly predisposed to react with cytochrome oxidase; therefore, the hypothesis that $\mathrm{H}_{2} \mathrm{~S}$ is also a potent antioxidant has been theorized. Recent studies have suggested that $\mathrm{H}_{2} \mathrm{~S}$ has the ability to react with ROS and RNS, including the superoxide radical anion, hydrogen peroxide, peroxynitrite, and hypochlorite ${ }^{[9,64,65]}$. Thus, a protective effect against organ damage caused by ROS and/or RNS may be proven. Because the concentration of $\mathrm{H}_{2} \mathrm{~S}$ in patients with $\mathrm{AD}$ is often severely suppressed and because $\mathrm{AD}$ has been proven to have a relationship with the increased generation of ROS and RNS, the role of $\mathrm{H}_{2} \mathrm{~S}$ in the cure of AD merits investigation ${ }^{[6,66]}$.

$\mathrm{H}_{2} \mathrm{~S}$ is also reported to have a specific relationship with NO. They both have a synergistic effect on vasodilation as well as an inhibitory effect on the twitching of the ileum stimulated by electricity. While NO may induce CSE activity and then enhance the production of $\mathrm{H}_{2} \mathrm{~S}, \mathrm{H}_{2} \mathrm{~S}$ also possess the ability to catalyze release of $\mathrm{NO}$ from $S$-nitrosoglutathione ${ }^{[67]}$. This type of relationship reveals a deeply unexplored mechanism between $\mathrm{H}_{2} \mathrm{~S}$ and NO. At a low concentration, $\mathrm{H}_{2} \mathrm{~S}$ displays only a weak relaxation of vessels, mainly due to the scavenging of NO. Thus, the specific concentration of $\mathrm{H}_{2} \mathrm{~S}$ play a critical role in determining its usability as a biomarker or its therapeutic application ${ }^{[68,69]}$.

\section{$\mathrm{H}_{2} \mathrm{~S}$ donor molecules and $\mathrm{H}_{2} \mathrm{~S}$-releasing drugs}

Ordinarily, $\mathrm{H}_{2} \mathrm{~S}$-related drugs are categorized as either administrators of $\mathrm{H}_{2} \mathrm{~S}$ that enhance local or whole-body $\mathrm{H}_{2} \mathrm{~S}$ concentrations and cause pathological and physiological changes or as inhibitors of $\mathrm{H}_{2} \mathrm{~S}$ production enzymes that reduce local or whole-body $\mathrm{H}_{2} \mathrm{~S}$ concentrations and cause pathological and physiological changes. $\mathrm{H}_{2} \mathrm{~S}$ donors, including donor molecules and $\mathrm{H}_{2} \mathrm{~S}$-releasing drugs, can be divided into three types: inorganic substances, such as NaHS; organic compounds, represented by GYY4137, which is derived from Lawesson's reagent; and agonists of $\mathrm{H}_{2} \mathrm{~S}$-synthesized enzymes. Inhibitors of enzymes involved in the synthesis of $\mathrm{H}_{2} \mathrm{~S}$ are of great importance, especially in the study of the mechanisms of $\mathrm{H}_{2} \mathrm{~S}$ functions. DL-propargylglycine, which easily permeates the cell membrane without obvious damage due to its high lipophilic property, is widely used as a nonspecific inhibitor of CSE and CBS. Disproof is a basic yet practical method for scientific investigation; therefore, the study of the effect of $\mathrm{H}_{2} \mathrm{~S}$ on certain targets by diminishing its concentration may be more 
effective than directly administering it. In fact, these inhibitors are effective agents in diseases induced by the overproduction of $\mathrm{H}_{2} \mathrm{~S}$.

\section{Inorganic $\mathrm{H}_{2} \mathrm{~S}$ donors}

Simple molecules, such as $\mathrm{NaHS}$ and $\mathrm{Na}_{2} \mathrm{~S}$, are basic tools used for $\mathrm{H}_{2} \mathrm{~S}$ research. Their donation of $\mathrm{H}_{2} \mathrm{~S}$ is rapid upon reaction with water because of high solubility. Gaseous $\mathrm{H}_{2} \mathrm{~S}$ is sometimes used by respiratory passages through direct absorption by pulmonary alveoli due to high bioavailability. However, there is a fundamental shortage of the use of inorganic $\mathrm{H}_{2} \mathrm{~S}$ donors in both research and clinical applications because of the need to attain long-term release at a controlled rate ${ }^{[70,71]}$. A too rapid release implies increasing the concentration of $\mathrm{H}_{2} \mathrm{~S}$ instantly, resembling a pulse cure, which is associated with a variety of problems, including concentrations that are too high for the local tissue and a lack of a long-term effect. Both problems led to imprecise experimental parameters, including dose and time, random results, and misleading causes. Thus, this data shortage may be a partial explanation for the emergence of divergent results, even when the same function is investigated.

To obtain a better $\mathrm{H}_{2} \mathrm{~S}$ donor for sustained and controlled use, organic compounds containing chemically synthesized molecules and natural plant extracts have become prevalent. Some organic compounds have shown ideal therapeutic effects and a large commercial potential.

\section{Precursors for endogenous $\mathrm{H}_{2} \mathrm{~S}$ synthesis}

$\mathrm{N}$-acetylcysteine and $L$-cysteine are precursors for endogenous $\mathrm{H}_{2} \mathrm{~S}$ synthesis ${ }^{[70]}$. Enhancing these precursors causes $\mathrm{H}_{2} \mathrm{~S}$ to increase with the catalysis of CSE and CBS. This precursor increase has minimal side effects associated with their production in the body.

\section{Synthetic $\mathrm{H}_{2} \mathrm{~S}$ donors}

As in other fields, synthetic drugs are predominant among $\mathrm{H}_{2}$ S-releasing drugs. GYY4137, a derivative of Lawesson's reagent, acts as a synthetic $\mathrm{H}_{2} \mathrm{~S}$ donor. Its sustained release of $\mathrm{H}_{2} \mathrm{~S}$ in aqueous media with a concentration above baseline has been demonstrated ${ }^{[72]}$. GYY4137 causes the concentrationdependent suppression of cancer cells, such as MCF-7, by the promotion of apoptosis without an obvious impact in normal cells, such as IMR90. That is to say, our demand for the sustained moderate release of $\mathrm{H}_{2} \mathrm{~S}$ is met. In a recent study, a series of new $\mathrm{H}_{2} \mathrm{~S}$ donors based on the $\mathrm{N}$-(benzoylthio)benzamide template were synthesized. The authors utilized the theory that the S-N bond is cysteine-activated under certain conditions, which needs to be demonstrated in future studies $^{[73]}$. The release rate could be manually adjusted by the purposeful modification of the core structure.

\section{$\mathrm{H}_{2} \mathrm{~S}$-nonsteroidal anti-inflammatory drug hybrids}

NSAIDs, among which aspirin is well known, are widely used for their anti-inflammatory and anti-gout properties. Nevertheless, they are associated with side effects, such as serious gastrointestinal bleeding and heart attack. Aspirin, as a delegate of NSAIDs, is famous for its anti-inflammatory ability as well as its prevention of atherosclerosis by inhibiting COX and platelet aggregation. However, aspirin also stimulates gastric bleeding and, worse, the prevention of platelet aggregation will hinder the cessation of bleeding. $\mathrm{H}_{2} \mathrm{~S}-\mathrm{NSAID}$ hybrids have, thus, been devised based on the protective effect of $\mathrm{H}_{2} \mathrm{~S}$ on the gastrointestinal and cardiovascular systems ${ }^{[74,75]}$. ATB 337, which is derived from diclofenac, shows significantly reduced gastrointestinal toxicity compared with diclofenac and has an enhanced anti-inflammatory effect with no effect on hematocrit or leukocyte adherence. ATB 429, which is derived from mesalamine, also shows an improvement in treating inflammatory bowel disease compared with its parent drug. ATB 346, which is derived from naproxen, remarkably reduces gastrointestinal and cardiovascular toxicity, such as the two aforementioned drugs ${ }^{[70]}$. The side effects of NSAIDs mainly come from the single inhibition of only COX-1 or COX-2, which generates an imbalance in the expression of COX-1 and COX-2 in different tissues and organs. Therefore, these $\mathrm{H}_{2} \mathrm{~S}$-NSAID hybrid compounds can release $\mathrm{H}_{2} \mathrm{~S}$ when dissolved by enzymes, which will protect organs, such as the stomach as well as the heart, because of the anti-oxidation or other effects of $\mathrm{H}_{2} \mathrm{~S}$. It should also be noted that these types of compounds are not a simple addition of both NSAIDs and $\mathrm{H}_{2} \mathrm{~S}$ but because they can affect each other when in the same place at the same time, they make a more magnified effect than a simple two part addition.

\section{Natural plant-derived compounds}

Vegetables, represented by garlic and ginger, are ordinary salubrious foods that have anti-inflammatory functions. In recent years, garlic-derived polysulfide compounds have drawn great attention due to their potential anti-inflammatory and anti-cancer effects. DATS is the first garlic-derived molecule discovered to possess vasoactivity along with the ability to specifically suppress cancer cells ${ }^{[76]}$. Compounds similar to DATS, such as DAS, DADS, and DATTS, have been evaluated for similar functions, but they are complicated. Different effects have been found. DAS reportedly activates the nuclear receptor CAR which induces various hepatic drugmetabolizing phase I and phase II enzymes in the mouse liver and preventive effects on some types of gastric cancer ${ }^{[77]}$. DADS has demonstrated vasorelaxation effect in aortic ring preparations via glucose- and thiol-dependent cellular reactions. Interestingly, DADS modified hemoglobin's $\beta$-chain at cysteine-93 or cysteine- $11_{2}$ in deoxygenated human red blood cells. This was the first instance of a garlic-derived compound that was shown to be able to modify an intracellular protein ${ }^{[77]}$. Normally, garlic-derived compounds are simply regarded as precursors of $\mathrm{H}_{2} \mathrm{~S}$ when absorbed and metabolized in blood. Therefore, because DADS itself is able to generate direct protein changes, it is worthy of future study.

$S$-allylcysteine is believed to have a cardioprotective effect and is a potential source of $\mathrm{H}_{2} \mathrm{~S}$. However, whether it plays a role as a $\mathrm{H}_{2} \mathrm{~S}$ precursor or a modulator of $\mathrm{H}_{2} \mathrm{~S}$-related enzymes 
is controversial ${ }^{[76]}$. Another novel garlic-derived compound, $S$-propargyl-cysteine, is now under investigation. It was recently shown to attenuate lipopolysaccharide-induced spatial learning and memory impairment through TNF signaling and the NF-KB pathway in rats, which contributes to studies about $\mathrm{AD}$ and other diseases related to neuronal damage ${ }^{[6,79]}$.

Compounds extracted from other plants display similar effects. Sulforaphane, which is derived from isothiocyanates found in cruciferous vegetables, exhibits an anti-cancer property. Sulforaphane suppresses the proliferation of prostate cancer cells and enhances the expression of CBS and CSE. In addition, sulforaphane activates p38 mitogen-activated protein kinase and c-Jun N-terminal kinase, suggesting a potent mechanism ${ }^{[80]}$. Although most of the significant results have been gained from in vitro studies, the study of $\mathrm{H}_{2} \mathrm{~S}$-releasing donors in vivo is more complex. Therefore, the identification of a feasible drug for clinical use requires further research.

\section{Future developments: challenges for translation of the toxic molecule $\mathrm{H}_{2} \mathrm{~S}$}

Investigation of the role of $\mathrm{H}_{2} \mathrm{~S}$ is still in its infancy. $\mathrm{H}_{2} \mathrm{~S}$ has both scientific and technological value. The latter tends to dominate because of its financial value and direct applicability, which substantiates research efforts. However, the scientific investigation of $\mathrm{H}_{2} \mathrm{~S}$ is also important for the elucidation of its base fundamental roles. Scientific investigation strives to address disease, enhance quality of life, and disclose the secrets of the human body. Certainly problems and challenges will arise and the limitations of experimental materials will at times constrain further $\mathrm{H}_{2} \mathrm{~S}$ research. A sustained and controlled $\mathrm{H}_{2} \mathrm{~S}$-releasing donor that functions both in vitro and in vivo has not yet been found. An effective and quick method of measuring the concentration of $\mathrm{H}_{2} \mathrm{~S}$ is also required, especially a non-invasive method. With an increased understanding of the various $\mathrm{H}_{2} \mathrm{~S}$ mechanisms in the body, further study of $\mathrm{H}_{2} \mathrm{~S}$ becomes more difficult and complicated. $\mathrm{H}_{2} \mathrm{~S}$ is known as a third gaseous signaling molecule, which means that it plays the role of a messenger. The concentration of $\mathrm{H}_{2} \mathrm{~S}$ has been proven to have relevance in particular diseases; for instance, it is overproduced in sepsis and found at inadequate levels in $\mathrm{AD}^{[81]}$. Therefore, the mechanism controlling the actual concentration of $\mathrm{H}_{2} \mathrm{~S}$ in certain tissues may become the ultimate problem for $\mathrm{H}_{2} \mathrm{~S}$ related research. It should be emphasized that a relevant relationship does not mean a relationship of causation. By regulating the $\mathrm{H}_{2} \mathrm{~S}$ concentration in particular tissues, symptoms of a specific disease can be controlled, which implies that the origin of the disease has not been addressed. That is to say, the regulation of $\mathrm{H}_{2} \mathrm{~S}$ can only provide transient protection from certain diseases, such as hypertension. The challenges of the sustained and controlled release of $\mathrm{H}_{2} \mathrm{~S}$-releasing drugs were mentioned above. Another difficulty in $\mathrm{H}_{2} \mathrm{~S}$ related research comes from the multiple functions of $\mathrm{H}_{2} \mathrm{~S}$, which cause a shortage of specific effects. The effects of $\mathrm{H}_{2} \mathrm{~S}$ are dose-, time-, and tissue-dependent. For patients with different diseases, $\mathrm{H}_{2} \mathrm{~S}$ may need to be administered as different drugs. Therefore, a focus on the general effects of $\mathrm{H}_{2} \mathrm{~S}$, such as on cardiovascular protection, is rational.

\section{Acknowledgements}

This study was supported by the National Basic Research Program (973 Program) (№ 2010CB 912603) and the National Natural Science Foundation (№ 30888002, № 30772565) of China.

\section{Abbreviations}

$\mathrm{H}_{2} \mathrm{~S}$, Hydrogen sulfide; $\mathrm{CO}$, carbon monoxide; NO, nitric oxide; CSE, cystathionine $\gamma$-lyase; CBS, cystathionine $\beta$-synthase; 3-MST, 3-mercaptopyruvate sulfurtransferase; NaHS, sodium hydrosulfide; AD, Alzheimer's disease; $K_{\text {ATP }}$ channels, potassium-dependent ATP-sensitive channels; TRP, transient receptor potential; TRPC, canonical transient receptor potential channel; TRPV, vanilloid transient receptor potential channel; TRPM, melastatin transient receptor potential channel; TRPP, polycystin transient receptor potential channel; TRPML, mucolipin transient receptor potential channel; TRPA, ankyrin transient receptor potential channel; $\mathrm{CHO}$ cells, Chinese hamster ovary cells; NF-KB, nuclear factor kappa-light-chain-enhancer of activated B cells; SFKs, SRC family kinases; ICAM-1, intracellular adhesion molecule-1; TRAF1, TNFR-associated factor 1; TRAF2, TNFR-associated factor 2; ROS, reactive oxygen species; RNS, reactive nitrogen species; NSAIDs, nonsteroidal anti-inflammatory drugs; DATS, diallyl trisulfide; DAS, diallyl sulfide; DADS, diallyl disulfide; DATTS, diallyl tetrasulfide; CAR, orphan member of the nuclear steroid hormone receptor superfamily.

\section{References}

$1 \mathrm{Li} \mathrm{L,} \mathrm{Hsu} \mathrm{A,} \mathrm{Moore} \mathrm{PK.} \mathrm{Actions} \mathrm{and} \mathrm{interactions} \mathrm{of} \mathrm{nitric} \mathrm{oxide,} \mathrm{carbon}$ monoxide and hydrogen sulphide in the cardiovascular system and in inflammation - a tale of three gases! Pharmacol Ther 2009; 123 : 386-400.

2 Lagoutte E, Mimoun S, Andriamihaja M, Chaumontet C, Blachier $F$, Bouillaud F. Oxidation of hydrogen sulfide remains a priority in mammalian cells and causes reverse electron transfer in colonocytes. Biochim Biophys Acta 2010; 1797: 1500-11.

3 Abe K, Kimura $\mathrm{H}$. The possible role of hydrogen sulfide as an endogenous neuromodulator. J Neurosci 1996; 16: 1066-71.

4 Olson KR. Is hydrogen sulfide a circulating "gasotransmitter" in vertebrate blood? Biochim Biophys Acta 2009; 1787: 856-63.

5 Predmore BL, Lefer DJ. Development of hydrogen sulfide-based therapeutics for cardiovascular disease. J Cardiovasc Translation Res 2010; 3: 487-98.

6 Gong QH, Wang Q, Pan LL, Liu XH, Xin H, Zhu YZ. S-propargylcysteine, a novel hydrogen sulfide-modulated agent, attenuates lipopolysaccharide-induced spatial learning and memory impairment: involvement of TNF signaling and NF-kappaB pathway in rats. Brain, behavior, and immunity 2011; 25: 110-9.

7 Kawabata A, Ishiki T, Nagasawa K, Yoshida S, Maeda Y, Takahashi T, et al. Hydrogen sulfide as a novel nociceptive messenger. Pain 2007; 132: $74-81$.

8 Wang R. Signaling pathways for the vascular effects of hydrogen sulfide. Curr Opin Nephrol Hypertens 2011; 20: 107-12.

9 Kimura $\mathrm{H}$. Hydrogen sulfide: its production, release and functions. Amino Acids 2011; 41: 113-21. 
10 Hughes MN, Centelles MN, Moore KP. Making and working with hydrogen sulfide: the chemistry and generation of hydrogen sulfide in vitro and its measurement in vivo: a review. Free Radic Biol Med 2009; 47: 1346-53.

11 Ishigami M, Hiraki K, Umemura K, Ogasawara Y, Ishii K, Kimura H. A source of hydrogen sulfide and a mechanism of its release in the brain. Antioxidants Redox Signaling 2009; 11: 205-14.

12 Cunha TM, Dal-Secco D, Verri WA Jr, Guerrero AT, Souza GR, Vieira $\mathrm{SM}$, et al. Dual role of hydrogen sulfide in mechanical inflammatory hypernociception. Eur J Pharmacol 2008; 590: 127-35.

13 Liu YY, Sparatore A, Del Soldato P, Bian JS. ACS84, a novel hydrogen sulfide-releasing compound, protects against amyloid $\beta$-induced cell cytotoxicity. Neurochem Int 2011; 58: 591-8.

$14 \mathrm{Qu} \mathrm{K}$, Lee S, Bian J, Low CM, Wong PH. Hydrogen sulfide: neurochemistry and neurobiology. Neurochem Int 2008; 52: 155-65.

15 Whiteman M, Winyard PG. Hydrogen sulfide and inflammation: the good, the bad, the ugly and the promising. Expert Rev Clin Pharmacol 2011; 4: 13-32. doi: 10.1586/ecp.10.134.

16 Tan BH, Wong PTH, Bian JS. Hydrogen sulfide: A novel signaling molecule in the central nervous system. Neurochem Int 2010; 56: 3-10.

17 Ufnal M, Sikora M, Dudek M. Exogenous hydrogen sulfide produces hemodynamic effects by triggering central neuroregulatory mechanisms. Acta Neurobiol 2008; 68: 382-8.

18 Wang MJ, Cai WJ, Li N, Ding YJ, Chen Y, Zhu YC. The hydrogen sulfide donor NaHS promotes angiogenesis in a rat model of hind limb ischemia. Antioxidants Redox Signaling 2010; 12: 1065-77.

19 Rossoni G, Manfredi B, Tazzari V, Sparatore A, Trivulzio S, Del Soldato $\mathrm{P}$, et al. Activity of a new hydrogen sulfide-releasing aspirin (ACS14) on pathological cardiovascular alterations induced by glutathione depletion in rats. Eur J Pharmacol 2010; 648: 139-45.

20 Li YF, Xiao CS, Hui RT. Calcium sulfide (CaS), a donor of hydrogen sulfide $\left(\mathrm{H}_{2} \mathrm{~S}\right)$ : A new antihypertensive drug? Med Hypothesis 2009; 73 : 445-47.

21 Perna AF, Luciano MG, Ingrosso D, Raiola I, Pulzella P, Sepe I, et al. Hydrogen sulfide, the third gaseous signaling molecule with cardiovascular properties, is decreased in hemodialysis patients. J Renal Nutr 2010; 20: S11-S14.

22 Sowmya S, Swathi Y, Yeo AL, Shoon ML, Moore PK, Bhatia M. Hydrogen sulfide: regulatory role on blood pressure in hyperhomocysteinemia. Vasc Pharmacol 2010; 53: 138-43.

23 Zhong G, Chen F, Cheng Y, Tang C, Du J. The role of hydrogen sulfide generation in the pathogenesis of hypertension in rats induced by inhibition of nitric oxide synthase. J Hypertens 2003; 21: 1879-85.

24 Qiao W, Chaoshu T, Hongfang J, Junbao D. Endogenous hydrogen sulfide is involved in the pathogenesis of atherosclerosis. Biochem Biophys Res Commun 2010; 396: 182-6.

25 Li W, Tang C, Jin H, Du J. Regulatory effects of sulfur dioxide on the development of atherosclerotic lesions and vascular hydrogen sulfide in atherosclerotic rats. Atherosclerosis 2011; 215: 323-30.

26 Szabó G, Veres G, Radovits T, Gerō D, Módis K, Miesel-Gröschel C, et al. Cardioprotective effects of hydrogen sulfide. Nitric Oxide 2011; 25: 201-10.

27 Ji Y, Pang Qf, Xu G, Wang L, Wang JK, Zeng YM. Exogenous hydrogen sulfide postconditioning protects isolated rat hearts against ischemia-reperfusion injury. Eur J Pharmacol 2008; 587: 1-7.

28 Nicholson CK, Calvert JW. Hydrogen sulfide and ischemia-reperfusion injury. Pharmacol Res 2010; 62: 289-97.

29 Fu Z, Liu X, Geng B, Fang L, Tang C. Hydrogen sulfide protects rat lung from ischemia-reperfusion injury. Life Sci 2008; 82: 1196-202.

30 Sodha NR, Clements RT, Feng J, Liu Y, Bianchi C, Horvath EM, et al.
Hydrogen sulfide therapy attenuates the inflammatory response in a porcine model of myocardial ischemia/reperfusion injury. J Thorac Cardiovasc Surg 2009; 138: 977-84.

31 Gao Y, Yao X, Zhang Y, Li W, Kang K, Sun L, et al. The protective role of hydrogen sulfide in myocardial ischemia-reperfusion-induced injury in diabetic rats. Int J Cardiol 2011; 152: 177-83.

32 Chunyu Z, Junbao D, Dingfang B, Hui Y, Xiuying T, Chaoshu T. The regulatory effect of hydrogen sulfide on hypoxic pulmonary hypertension in rats. Biochem Biophys Res Commun 2003; 302: 810-6.

33 Tang C, Li X, Du J. Hydrogen sulfide as a new endogenous gaseous transmitter in the cardiovascular system. Curr Vasc Pharmacol 2006; 4: 17-22.

34 Hongfang J, Bailin C, Bin Z, Chunyu Z, Xinmin L, Weijin Z, et al. Effects of hydrogen sulfide on hypoxic pulmonary vascular structural remodeling. Life Sci 2006; 78: 1299-309.

35 Linden DR, Levitt MD, Farrugia G, Szurszewski JH. Endogenous production of $\mathrm{H}_{2} \mathrm{~S}$ in the gastrointestinal tract still in search of a physiologic function. Antioxidants Redox Signaling 2010; 12: 1135-46.

36 Ganster F, Burban M, de la Bourdonnaye M, Fizanne L, Douay O, Loufrani $L$, et al. Effects of hydrogen sulfide on hemodynamics, inflammatory response and oxidative stress during resuscitated hemorrhagic shock in rats. Crit Care 2010; 14: R165.

37 Wallace JL. Hydrogen sulfide-releasing anti-inflammatory drugs. Trends Pharmacol Sci 2007; 28: 501-5.

38 Wallace JL, Vong L, McKnight W, Dicay M, Martin GR. Endogenous and exogenous hydrogen sulfide promotes resolution of colitis in rats. Gastroenterology 2009; 137: 569-78.

39 Chávez-Piña AE, Tapia-Álvarez GR, Navarrete A. Inhibition of endogenous hydrogen sulfide synthesis by PAG protects against ethanol-induced gastric damage in the rat. Eur J Pharmacol 2010; 630: 131-6.

40 Zins KA, Ordog T, Bardsley MR, Farrugia G, Levitt MD, Slungaard A, et al. T2049 hydrogen sulfide ameliorates murine experimental colitis through specific effects on diverse classes of infiltrating immune cells. Gastroenterology 2010; 138: S-621.

41 Tamizhselvi R, Koh YH, Sun J, Zhang H, Bhatia M. Hydrogen sulfide induces ICAM-1 expression and neutrophil adhesion to caeruleintreated pancreatic acinar cells through NF-KB and Src-family kinases pathway. Exp Cell Res 2010; 316: 1625-36.

42 Morselli-Labate AM, Fantini L, Pezzilli R. Hydrogen sulfide, nitric oxide and a molecular mass $66 \mathrm{u}$ substance in the exhaled breath of chronic pancreatitis patients. Pancreatology 2007; 7: 497-504.

43 Bhatia M, Sidhapuriwala J. M1829 proinflammatory effects of hydrogen sulfide on substance $P$ in caerulein-induced acute pancreatitis. Gastroenterology 2008; 134: A-428.

44 Wee EWL, Bhatia M, Fernandes ML, Madhavan K, Wong JY, Yeo AL, et al. T1301 serum hydrogen sulfide and substance $P$ are early clinical predictors of the severity of acute pancreatitis. Gastroenterology 2009; 136: A-543.

45 Tay AS, Hu LF, Lu M, Wong PT, Bian JS. Hydrogen sulfide protects neurons against hypoxic injury via stimulation of ATP-sensitive potassium channel/protein kinase C/extracellular signal-regulated kinase/heat shock protein 90 pathway. Neuroscience 2010; 167: 277-86.

46 Kiyonaga T, Mitsui T, Torikoshi M, Takekawa M, Soejima T, Tada $\mathrm{H}$. Ultrafast photosynthetic reduction of elemental sulfur by $\mathrm{Au}$ nanoparticle-loaded $\mathrm{TiO}_{2}$. J Phys Chem B 2006; 110: 10771-8.

47 Łowicka E BJ. Hydrogen sulfide $\left(\mathrm{H}_{2} \mathrm{~S}\right)$ - the third gas of interest for pharmacologists. Pharmacol Rep 2007; 59: 4-24.

48 Sun WH, Liu F, Chen Y, Zhu YC. Hydrogen sulfide decreases the levels of ROS by inhibiting mitochondrial complex IV and increasing SOD activities in cardiomyocytes under ischemia/reperfusion. Biochem 
Biophys Res Commun 2012; 421: 164-9.

49 Maeda Y, Aoki Y, Sekiguchi F, Matsunami M, Takahashi T, Nishikawa H, et al. Hyperalgesia induced by spinal and peripheral hydrogen sulfide: evidence for involvement of Cav3.2 T-type calcium channels. Pain 2009; 142: 127-32.

50 Okubo K, Takahashi T, Sekiguchi F, Kanaoka D, Matsunami M, Ohkubo $\mathrm{T}$, et al. Inhibition of T-type calcium channels and hydrogen sulfideforming enzyme reverses paclitaxel-evoked neuropathic hyperalgesia in rats. Neuroscience 2011; 188: 148-56.

51 Takahashi T, Aoki Y, Okubo K, Maeda Y, Sekiguchi F, Mitani K, et al. Upregulation of $\mathrm{Ca}(\mathrm{v}) 3.2 \mathrm{~T}$-type calcium channels targeted by endogenous hydrogen sulfide contributes to maintenance of neuropathic pain. Pain 2010; 150: 183-91.

52 Bauer CC, Boyle JP, Porter KE, Peers C. Modulation of $\mathrm{Ca}^{2+}$ signalling in human vascular endothelial cells by hydrogen sulfide. Atherosclerosis 2010; 209: 374-80.

53 Matsunami M, Kirishi S, Okui T, Kawabata A. Chelating luminal zinc mimics hydrogen sulfide-evoked colonic pain in mice: possible involvement of T-type calcium channels. Neuroscience 2011; 181: 257-64.

$54 \mathrm{MC} \mathrm{M}$. Editorial comment on distribution and function of the hydrogen sulfide-sensitive TRPA1 ion channel in rat urinary bladder. Eur Urol 2008; 53: 399-400.

55 Streng T, Axelsson HE, Hedlund P, Andersson DA, Jordt SE, Bevan S, et al. Distribution and function of the hydrogen sulfide-sensitive TRPA1 ion channel in rat urinary bladder [Research Support, Non-US Gov't]. Eur Urol 2008; 53: 391-9.

56 Miyamoto R, Otsuguro K, Ito S. Time- and concentration-dependent activation of TRPA1 by hydrogen sulfide in rat DRG neurons. Neurosci Lett 2011; 499: 137-42.

57 Chattopadhyay M, Kodela R, Nath N, Barsegian A, Boring D, Kashfi K. Hydrogen sulfide-releasing aspirin suppresses NF-kappaB signaling in estrogen receptor negative breast cancer cells in vitro and in vivo. Biochem Pharmacol 2012; 83: 723-32.

58 Tamizhselvi R, Koh YH, Sun J, Zhang H, Bhatia M. Hydrogen sulfide induces ICAM-1 expression and neutrophil adhesion to caeruleintreated pancreatic acinar cells through NF-kappaB and Src-family kinases pathway. Exp Cell Res 2010; 316: 1625-36.

59 Sen N, Paul BD, Gadalla MM, Mustafa AK, Sen T, Xu R, et al. Hydrogen sulfide-linked sulfhydration of NF-kappaB mediates its antiapoptotic actions. Mol Cell 2012; 45: 13-24.

60 Caro A, Kauffman T, Tackett J, Thompson S. Increased oxidative stress and cytotoxicity by hydrogen sulfide in HepG2 cells overexpressing CYP2E1. Cell Biol Toxicol 2011; 27: 439-53.

61 Forgan LG, Forster ME. Oxygen consumption, ventilation frequency and cytochrome $c$ oxidase activity in blue cod (Parapercis colias) exposed to hydrogen sulphide or isoeugenol. Comp Biochem Physiol Toxicol Pharmacol: CBP 2010; 151: 57-65.

62 Baumgart K, Radermacher P, Wagner F. Applying gases for microcirculatory and cellular oxygenation in sepsis: effects of nitric oxide, carbon monoxide, and hydrogen sulfide. Curr Opin Anaesthesiol 2009; 22: 168-76.

63 Wagner F, Asfar P, Calzia E, Radermacher P, Szabo C. Bench-to-bedside review: hydrogen sulfide - the third gaseous transmitter: applications for critical care. Crit Care 2009; 13: 213.

64 Mancardi D, Penna C, Merlino A, Del Soldato P, Wink DA, Pagliaro P. Physiological and pharmacological features of the novel gasotransmitter: hydrogen sulfide. Biochim Biophys Acta 2009; 1787: 864-72.

65 Whiteman M, Moore PK. Hydrogen sulfide and the vasculature: a novel vasculoprotective entity and regulator of nitric oxide bioavailability?

J Cell Mol Med 2009; 13: 488-507.

66 Qu K, Lee SW, Bian JS, Low CM, Wong PT. Hydrogen sulfide: neurochemistry and neurobiology. Neurochem Int 2008; 52: 155-65.

67 Kimura $\mathrm{H}$. Hydrogen sulfide: its production, release and functions. Amino Acids 2011; 41: 113-21.

68 Zhang F, Li X, Stella C, Chen L, Liao Y, Tang C, et al. Plasma hydrogen sulfide in differential diagnosis between vasovagal syncope and postural orthostatic tachycardia syndrome in children. J Pediatrics 2012; 160: 227-31.

69 Yang J, Zhao J, Du S, Liu D, Fu C, Li X, et al. Postural orthostatic tachycardia syndrome with increased erythrocytic hydrogen sulfide and response to midodrine hydrochloride. J Pediatr 2013. doi: 10.1016/ j.jpeds.2013.04.039.

70 Caliendo G, Cirino G, Santagada V, Wallace JL. Synthesis and biological effects of hydrogen sulfide $\left(\mathrm{H}_{2} \mathrm{~S}\right)$ : development of $\mathrm{H}_{2} \mathrm{~S}$-releasing drugs as pharmaceuticals. J Med Chem 2010; 53: 6275-86.

71 Ishigami M, Hiraki K, Umemura K, Ogasawara Y, Ishii K, Kimura $\mathrm{H}$. A source of hydrogen sulfide and a mechanism of its release in the brain. Antioxidants Redox Signal 2009; 11: 205-14.

72 Lee ZW, Zhou J, Chen CS, Zhao Y, Tan CH, Li L, et al. The slowreleasing hydrogen sulfide donor, GYY4137, exhibits novel anti-cancer effects in vitro and in vivo. Plos One 2011; 6: e21077.

73 Zhao $\mathrm{Y}$, Wang $\mathrm{H}$, Xian M. Cysteine-activated hydrogen sulfide $\left(\mathrm{H}_{2} \mathrm{~S}\right)$ donors. J Am Chem Soc 2011; 133: 15-7.

74 Chattopadhyay M, Kodela R, Nath N, Dastagirzada YM, VelazquezMartinez CA, Boring D, et al. Hydrogen sulfide-releasing NSAIDs inhibit the growth of human cancer cells: a general property and evidence of a tissue type-independent effect. Biochem Pharmacol 2012; 83: 715-22.

75 Chattopadhyay M, Kodela R, Olson KR, Kashfi K. NOSH-aspirin (NBS1120), a novel nitric oxide- and hydrogen sulfide-releasing hybrid is a potent inhibitor of colon cancer cell growth in vitro and in a xenograft mouse model. Biochem Biophys Res Commun 2012; 419: 523-8.

76 Jacob C, Anwar A, Burkholz T. Perspective on recent developments on sulfur-containing agents and hydrogen sulfide signaling. Planta Med 2008; 74: 1580-92.

77 Sueyoshi T, Green WD, Vinal K, Woodrum TS, Moore R, Negishi M. Garlic extract diallyl sulfide (DAS) activates nuclear receptor car to induce the sult1e1 gene in mouse liver. PLoS One 2011; 6: e21229.

78 Bonaventura J, Rodriguez EN, Beyley V, Vega IE. Allylation of intraerythrocytic hemoglobin by raw garlic extracts. J Med Food 2010; 13: 943-9.

79 Sidhapuriwala JN, Hegde A, Ang AD, Zhu YZ, Bhatia M. Effects of Spropargyl-cysteine (SPRC) in caerulein-induced acute pancreatitis in mice. Plos One 2012; 7: e32574.

80 Pei Y, Wu B, Cao Q, Wu L, Yang G. Hydrogen sulfide mediates the antisurvival effect of sulforaphane on human prostate cancer cells. Toxicol Appl Pharmacol 2011; 257: 420-8.

81 Gong QH, Shi XR, Hong ZY, Pan LL, Liu XH, Zhu YZ. A new hope for neurodegeneration: possible role of hydrogen sulfide. J Alzheimers Dis 2011; 24: 173-82.

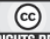

SOMERTIGHSHESER Derivative Works 3.0 Unported License. To view a copy of this license, visit http://creativecommons.org/licenses/ by-nc-nd/3.0/ 